\title{
Surveys of wintering Little Bustards Tetrax tetrax in central Spain: distribution and population estimates at a regional scale
}

\author{
ELADIO L. GARCÍA DE LA MORENA, MANUEL B. MORALES, EDUARDO DE \\ JUANA and FRANCISCO SUÁREZ
}

\section{Summary}

Developing a standardized survey methodology to census and estimate the size of wintering populations is a main conservation priority for the endangered Little Bustard. We present a standard and repeatable methodology to census wintering Little Bustard populations at a regional scale, and the first statistically reliable population estimate of a Little Bustard wintering population in Spain. We carried out two surveys, in 2003 and 2004, using UTM $10 \mathrm{~km} \times 10 \mathrm{~km}$ squares as census units, which were subjected to stratified sampling over the species' potential distribution range in the region of Madrid (Central Spain). Only the areas of potentially suitable habitat within squares of known winter presence of the species were considered. The species' winter distribution in Madrid was fairly constant between years, showing a fragmented pattern in three main nuclei. The number of Little Bustards observed was consistent between surveys (752 and 786 birds, respectively), with birds grouped in an average of 32 flocks ( 1 to 350 birds, mean $=27.9$ birds). No between-winter differences in flock size were observed, although differences between sectors were significant. The highest densities were observed in the Tagus valley (mean density $=2.9$ birds $\mathrm{km}^{-2}, 293$ birds), followed by north-eastern farmland (mean density $=0.6$ bird $\mathrm{km}^{-2}, 269$ birds). The estimated size of the Little Bustard population wintering in the Madrid region was 1,051 (95\% CI $=1,043-1,231$ ). This calculation was based on recorded population density, measured as the number of birds per square kilometre, and considers the potential habitats available in each sector. We propose this methodology as adequate for surveying any Little Bustard wintering area, at both regional and smaller spatial scales. Survey results are consistent with previous tentative estimates for the region of Madrid, and with available information on Little Bustard movements. Sixty-five per cent of squares with Little Bustard presence were outside any protected area, which makes the wintering Little Bustard population of Madrid highly vulnerable to habitat disappearance and may affect the viability of breeding nuclei whose individuals winter in the region.

\section{Introduction}

Winter is a critical period for the survival of birds breeding in temperate areas, at both individual and population levels (i.e. Wiens 1989, Newton 1998), and therefore knowledge of winter ecology, movements and distribution is essential to a complete understanding of a species' biological cycle, as well as to the design of adequate conservation strategies (Rappole and McDonald 1994, Sherry and Holmes 1996, Newton 1998, Suárez 2004).

The Little Bustard Tetrax tetrax is a Palaearctic, medium-sized steppe bird of the Otididae family whose main habitat in western Europe corresponds to extensive cereal farmland, although 
it can also be found in natural steppe and extensive pastureland (Snow and Perrins 1998, Martínez 1994, Salamolard and Moreau 1999, Wolff et al. 2001, Morales et al. 2005a). Although the Iberian populations of the species have been classified as sedentary or dispersive by different authors (i.e. Bernis 1966-1971, Cramp and Simmons 1980, Díaz et al. 1996), many populations can actually be considered as migratory or partially migratory since they completely or partly disappear from their breeding grounds, performing regular medium- or long-distance movements and concentrating in certain wintering sites (Morales et al. 2002, García de la Morena et al. 2004a, own unpubl. data). In spite of recent findings, however, current information on the winter distribution and abundance of Little Bustards in Spain is still limited (García de la Morena 2002, García de la Morena et al. 2004b).

The Little Bustard has undergone a severe population decline throughout its range in recent decades (Goriup 1994, Del Hoyo et al. 1996), and disappeared from many European countries (Schulz 1985). It is currently classified as Near Threatened globally (Collar et al. 1994) and Vulnerable in Europe (BirdLife International 2004) and Spain (García de la Morena et al. 2004b). Seventy to eighty per cent of the European population is concentrated in Spain (BirdLife International 2004, García de la Morena et al. 2003, 2004b). A recent update of the species' population status and distribution in Spain has in fact confirmed steep reductions over the last 30 years in those regions where either agriculture intensification or habitat transformation (irrigation, introduction of new cultures; infrastructures and urbanization) have occurred more intensively (García de la Morena et al. 2004b, Suárez 2004).

Among other conservation priorities on monitoring and research, the species' European Action Plan (De Juana and Martínez 2001) highlights the need to standardize census methods so they can be used throughout the range of the species in order to develop and implement an international monitoring programme. It also emphasizes the need to carry out an inventory and census of the wintering concentrations, particularly in the Iberian Peninsula.

In spite of this and the species' declining trends, no reliable estimate for the Iberian population is available. De Juana and Martínez (1996) made an estimate of 100,000-200,00o breeding males in Spain, although a more recent review yielded around 50,000-100,000 breeding males (García de la Morena et al. 2004b), and the Portuguese population is estimated at around 10,000-20,000 individuals (BirdLife International 2004). Neither estimate, however, is based on a standardized and repeatable methodology for large-scale (regional or national) censuses. Additionally, these and other figures are based on breeding numbers, which consider only males, since reproductive females and juveniles are highly discreet and undetectable, so that sex ratios of most Iberian populations are largely unknown. These limitations make real population sizes very difficult to calculate. In contrast, wintering Little Bustards gather in relatively large mixed flocks that tend to concentrate in certain areas (Cramp and Simmons 1980, García de la Morena et al. 2004b, own unpubl. data), therefore providing winter surveys with two main advantages: (i) estimates can be made for the entire population (males plus females and juveniles), and (ii) if main wintering quarters are located, the main body of the population can be counted, thus reducing estimates or extrapolation errors. Consequently, winter surveys may be preferable to breeding censuses in terms of estimating the size of the Iberian population of the species and, therefore, a very important percentage $(>90 \%)$ of all Little Bustards in Western Europe. Therefore, although our aim in the present study was to survey wintering Little Bustards, and to assess the suitability of the method at a regional scale, this method may be applied to a national or Iberian scale if the required survey effort could be coordinated. Nevertheless, the gregarious behaviour of birds and the relatively low detectability of flocks raise several methodological problems, both in survey design and the subsequent estimates, and impose the need for previous knowledge on the species' potential winter distribution, habitat preferences and flocking behaviour (Bibby et al. 2000). Regarding previous knowledge on the species' range, there is little information on its winter distribution, although some regional atlases have been done in some areas of Spain and Portugal (Pinto 1999; García de la Morena 2002). Moreover, the systematic review of wintering records from literature, bird reports, etc., could provide valuable information on distribution and 
location of main wintering areas of the species in Spain and elsewhere (García de la Morena et al. in prep.).

Here we present the results of two regional-scale Little Bustard winter censuses carried out in two consecutive years in the province of Madrid (central Spain), and propose a standardized winter census methodology, discussing its applicability to larger scale surveys and future monitoring programmes, and thus contributing to a major claim of the species' Action Plan. Additionally, our results are discussed in relation to the available information on the species' winter distribution and movements in central Spain, and their implications for the conservation of the Little Bustard in the region.

\section{Methods}

\section{Study area}

The region of Madrid is located in Central Spain between $41^{\circ} 10^{\prime} \mathrm{N}$ and $39^{\circ} 53^{\prime} \mathrm{N}$, and $4^{\circ} 35^{\prime} \mathrm{W}$ and $3^{\circ} \mathrm{O}^{\prime} \mathrm{W}$ and occupies about $8,000 \mathrm{~km}^{2}$. It can be broadly divided into two main geographical units: the mountains of the Iberian Central Range, which run along the north-east to south-west limit of the region over $900 \mathrm{~m}$, and the plains, which extend over the rest of the region as part of the Spanish Southern Plateau, at between 440 and $900 \mathrm{~m}$ elevation. The plains are made up of many different habitats, including extensive pastures, shrubs, forests, and urban areas, although extensive cereal or mosaic (with interspersed olive groves and vineyards) farmland is dominant. They also hold the highest human population density, most of the inhabitants (approx. 5.8 million) being concentrated in Madrid city, and its surroundings.

Breeding Little Bustards are widely distributed over the plains (Díaz et al. 1994, García de la Morena et al.. 2001), and their presence and abundance are positively correlated with landscape heterogeneity and the proportion of arable land (Morales et al. 2005a). Winter distribution is more restricted and localized (García de la Morena 2002), occupying mainly areas of extensive cereal farming but also other habitats, such as broom (Retama sphaerocarpa) shrublands or irrigated alfalfa (Medicago sativa) fields.

\section{Survey design}

Surveys were carried out in early February 2003 and late January 2004. In order to obtain a statistically reliable population estimate, stratified sampling was carried out over the species' potential winter range in the region (Bibby et al. 2000) using UTM $10 \mathrm{~km} \times 10 \mathrm{~km}$ squares as census units (Figure 1 ). To determine the potential winter range, we considered all squares with reported winter presence of the species over the last 10 years (García de la Morena 2002, own unpubl. data) together with those that, even if they had no presence records, were adjacent to squares with reports of more than 1o individuals and included potential Little Bustard winter habitats. We classified as potential winter habitats for the species any habitat type reported to hold wintering Little Bustards, either in the literature (i.e. García de la Morena 2002; Silva et al. 2004) or in our own database: extensive pasturelands; non-irrigated crops (extensive cereal crops and vineyards); mosaics of non-irrigated crops with other cultures (olive groves, irrigated crops); wastelands; broom shrublands; and wastelands in suburban areas. This habitat classification is based on the official 1:50,000 habitat cartography of the region (CAM 1998). We stratified the potential winter range into areas where population density was expected to be high, selecting for surveying all the squares with more than 10 birds recorded, and areas where the population was probably small. The remaining squares (those with fewer than 1o birds recorded or adjacent to squares with more than 1o birds), were randomly sampled. Moreover, we divided the species' potential winter range in the region into eight survey sectors which could be treated as separate territorial units due to their distinctive and homogeneous physiography, landscape and main land uses (Figure 1 , Table 1 ). 


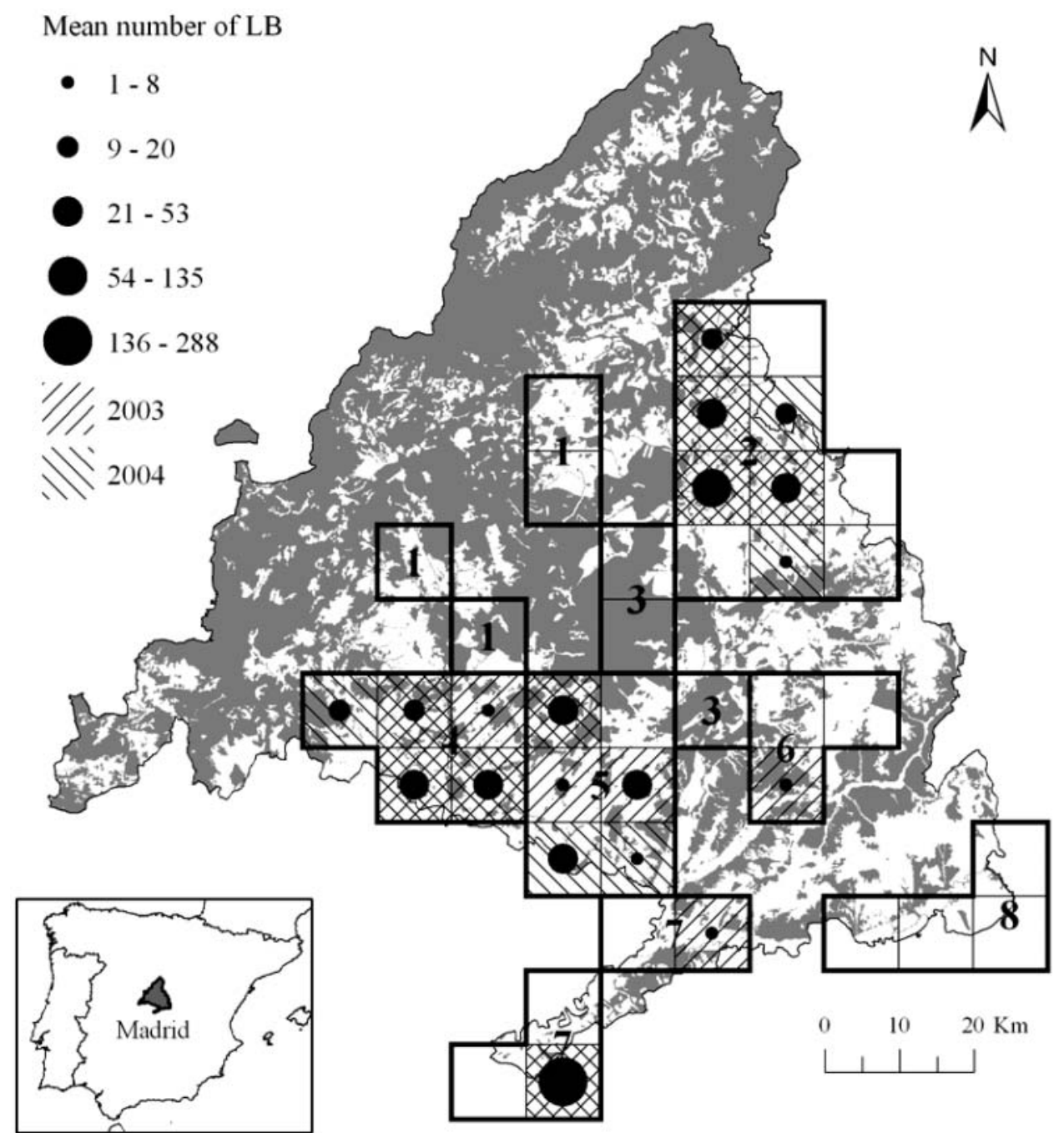

Figure 1. Mean numbers of Little Bustard (LB) per 1o km UTM square (thin lines) and years (diagonal lines). Potential habitats (in white) and survey sectors (thick lines): 1 , Escarpment pasturelands; 2, North-eastern croplands; 3, Madrid suburban area; 4, South-western croplands; 5, Southern croplands; 6, Campo Real plateau; 7, Tagus valley; 8, South-east.

In 2003 the potential winter range of the species was estimated in 51 squares, while in 2004 the estimate increased to 63 squares, since new areas with reported presence were added. The overall number of squares surveyed was $40(78 \%$ of the estimated potential range, 32 of them with known winter presence) in 2003 and 55 ( $87 \%$ of the potential range, 38 squares with known winter presence) in 2004. In order to optimize survey effort, within each square only potential Little Bustard winter habitats were prospected, these being identified using published 1:50,000 scale habitat cartography for the region of Madrid (CAM 1998). In squares shared with other provinces, only the portions included in Madrid were considered. Total survey cover in relation to potential habitat per sector and census year is presented in Table 1 . 
Table 1 . Area of potential winter range of the Little Bustard in the Madrid region in each survey sector, and the proportion of that range covered by the survey each year, together with the corresponding mean values.

\begin{tabular}{|c|c|c|c|c|c|c|c|}
\hline \multirow[t]{2}{*}{ Sector } & \multirow{2}{*}{$\frac{\text { Winter range }^{\mathrm{a}}}{\mathrm{km}^{2}}$} & \multicolumn{2}{|c|}{ Survey cover 2003} & \multicolumn{2}{|c|}{ Survey cover 2004} & \multicolumn{2}{|c|}{ Mean cover } \\
\hline & & $\mathrm{km}^{2}$ & $(\%)$ & $\mathrm{km}^{2}$ & $(\%)$ & $\mathrm{km}^{2}$ & $(\%)$ \\
\hline Escarpment pasturelands & 197.0 & 14.1 & $(7.2)$ & 50.5 & $(25.6)$ & 32.3 & $(16.4)$ \\
\hline North-eastern croplands & 568.6 & 466.3 & $(82.0)$ & 476.5 & $(83.8)$ & 471.4 & $(82.9)$ \\
\hline Madrid suburban area & 70.3 & 13.6 & (19.3) & 33.4 & $(47 \cdot 5)$ & $23 \cdot 5$ & $(33.4)$ \\
\hline South-western croplands & 319.0 & 195.2 & $(54.8)$ & 214.1 & (6o.1) & 204.6 & $(57 \cdot 5)$ \\
\hline Southern croplands & 356.0 & 238.8 & $(74 \cdot 9)$ & $207 \cdot 3$ & $(65.0)$ & 223.1 & $(69.9)$ \\
\hline Campo Real plateau & 191.5 & 131.3 & $(68.6)$ & 131.3 & $(68.6)$ & 131.3 & $(68.6)$ \\
\hline Tagus valley & 140.1 & 104.1 & $(74 \cdot 3)$ & 101.1 & $(72.2)$ & 102.6 & $(73.2)$ \\
\hline South-east & 118.3 & $75 \cdot 5$ & $(63.8)$ & 77.0 & $(65.1)$ & 76.2 & $(64.4)$ \\
\hline Total & 1960.9 & 1238.8 & $(63.2)$ & 1291.1 & $(65.8)$ & 1265.0 & $(64.5)$ \\
\hline
\end{tabular}

${ }^{a}$ Winter range is the known winter distribution of the species.

\section{Little Bustard counts}

Each square was surveyed using the look-see counting and mapping method (Bibby et al. 200o), adapted for a large-scale area. Potential habitat areas were covered by car at low speed (15-2O $\mathrm{kph}$ ) along all available roads and tracks to assure homogeneous survey effort. Stops were made every 500-1,000 m, normally at high-visibility points, to visually scan the area for Little Bustard flocks. All tracks within each square were covered, so that most fields or groups of fields were scanned from different observation points, thus allowing precise mapping and between-flock discrimination. Exhaustive scrutiny of the terrain (culture plots, field margins, shrubs, etc.) was normally required due to the secretive behaviour of Little Bustards out of the breeding season, even when they gather in large flocks. Once a group was detected, it was observed ad libitum until all birds were finally recorded. If observers felt that part of the flock could have been missed, they moved towards the birds so they would raise their heads, in order that they could be counted thoroughly (if the flock was flying, it was tracked visually and its landing point recorded to avoid potential duplication). Each square was censused by a team of one or two observers provided with 8-10 $\times 40$ binoculars and $20-40 \times 80$ telescopes, as well as the corresponding topographic and habitat cartography. Detected flocks were located on 1:50,000 scale topographic maps and their movements recorded if observed. Potential double counts within and between squares were later evaluated on the basis of their proximity, date and hour of observation. The areas covered and not covered in each square were also recorded on the maps provided. Surveys were performed during the entire daytime period, avoiding the hours around midday, when the activity of the Little Bustard is normally lower. The total number of days required to cover all selected squares was 3 in both years, while the number of survey teams was 13 in 2003 and 16 in 2004 (range of squares per team in both censuses: 1-6). To assist the statistical design of the study, surveyors did not know the strata (high or low) into which the squares they had been allocated fell (Bibby et al. 2000).

\section{Population estimates}

We counted the number of Little Bustards recorded in each square and estimated the number of birds per square after subtracting double counts. A minimum total of birds was thus obtained by summing the square numbers, both for each sector and for the whole study area. Given that not all potentially suitable habitats were surveyed and their area differs between squares and sectors, an estimate was calculated by extrapolating the number of birds per square kilometre to the total 
area of potential habitat within the species' winter distribution range. This extrapolation was based on the equation (Bibby et al. 2000):

$$
N=n \times A / a
$$

where $N$ is the estimated population size, $n$ is the number of birds recorded, $A$ is the potentially suitable area in the species' known winter distribution range $\left(1,960.9 \mathrm{~km}^{2}\right)$ and $a$ is the area of potential Little Bustard habitat surveyed in the squares (Table 1). For the population estimate, only the area of potential winter habitat within the squares of known winter presence of the species was considered, independently of the numbers of birds recorded. This estimate was made for each of the eight geographical sectors considered. Sector values were summed to give an overall figure for Madrid province. Because of the non-parametric and skewed distribution of counts and differing sample fractions between the different sectors of Madrid, $95 \%$ confidence intervals were calculated by means of a bias corrected and accelerated (BCa) bootstrapping procedure (Efron and Tibshirani 1986). Yearly variability in the sampled squares was calculated as the corresponding coefficient of variation.

Census differences between survey sectors were analysed by means of a chi-square test, while inter-annual and between-sector differences in flock size were assessed using non-parametric Kruskal-Wallis ANOVAs. The probability level of significance was set at $P=0.05$.

\section{Results}

\section{Little Bustard distribution and population size}

The percentage area of potential Little Bustard winter habitat surveyed in the winter range of the species during the 2003 and 2004 censuses was, respectively, $63.2 \%$ and $65.8 \%\left(1,265 \mathrm{~km}^{2}\right.$ on average; Table 1 ). Considering both years, the overall number of different squares in which the species was detected was 19, which corresponds to $47.5 \%$ of the potential winter range (no Little Bustard was observed out of this range in either census or outside the known winter range where the population estimations were done), and $16.5 \%$ of the region of Madrid (Figure 1 ). The number of squares with presence each winter was 14 , both surveys showing a fairly constant inter-annual distribution pattern at regional scale (Figure 1 ). The greatest variations at sector scale were found in areas such as 'Southern croplands' where only 1 of 5 squares showed presence in both years. No Little Bustards were detected in the 'Escarpment pasturelands', 'Madrid suburban area' and 'South-east' sectors.

Survey counts are provided in Table 2 . The two censuses yielded very similar numbers at a regional scale: 786 and 752 individuals in 2003 and 2004, respectively (mean value, 769 : $\mathrm{CV}=$ $3 \%)$ At sector scale, there were differences between years $\left(\chi_{4}^{2}=66.84, P<0.001\right)$. The greatest differences were due to changes in numbers in the 'North-eastern croplands' and "Tagus valley" sectors: in the first sector 94 more individuals were detected in 2004 than in the previous year $(\mathrm{CV}=25 \%)$, while in the latter the number of Little Bustards counted decreased by 141 individuals with respect to $2003(\mathrm{CV}=33 \%)$. On the other hand, in sectors such as 'Southwestern croplands' or 'Southern croplands' the results were more similar, with differences of only $1(\mathrm{CV}=1 \%)$ and $9(\mathrm{CV}=5 \%)$ birds between surveys, respectively.

Birds were grouped, on average, in 32 flocks of variable size, ranging from 1 to 350 individuals (mean value 27.9). Flock size did not differ statistically between winters (Kruskal-Wallis test: $H$ $=0.55, P=0.46, n=60$ ), although differences were significant between sectors (Kruskal-Wallis test: $H=11.69, P=<0.01, n=60$ ) with the lowest values in the 'Southern croplands' and the highest in the 'Tagus valley', where the biggest Little Bustard concentrations were found (largest flock size, 361 birds in 2003, average 293; mean Little Bustard density, 2.9 birds $\mathrm{km}^{-2}$ ). The sector with the next-highest Little Bustard concentrations was 'North-eastern croplands', where the average number of birds was 269 (maximum number, 316 in 2004; average density, 0.6 individuals $\mathrm{km}^{-2}$ ). In 'Southern croplands' and 'South-western croplands' observed densities 
were of the same order of magnitude, although the mean number of birds observed in these sectors was smaller (c. Ioo Little Bustards). In the remaining sectors, survey results were negative in both censuses, except for the 'Campo Real plateau', where a solitary individual was observed in 2003.

The estimated size of the Little Bustard population wintering in the region of Madrid was 1,051 (95\% CI $=1043-1231$ ) birds, while the minimum number of birds counted was 752 (Table 2). At sector scale, population estimates differed between winters, as shown above, although no differences were detected in 'Southern croplands'. The main nuclei were those included in the 'Tagus valley' sector, with 400 birds, and the 'North-eastern croplands' sector, with 324 Little Bustards, followed by the 'Southern croplands' and 'South-western croplands' sectors, with 164 and 161 birds, respectively (Table 2 ).

\section{Discussion}

\section{Census methodology and population estimates}

Our results are the first estimate of a wintering Little Bustard population in Spain and show that this census method is adequate for regional-scale surveys supported by a statistically reliable framework. The overall results, at regional scale, were consistent between years as regards both total numbers and distribution of the species. These numbers were very close to the broad estimate of 800-1,00o individuals given for the region of Madrid by García de la Morena (2002), which was the only figure previously available, although based on a non-systematic compilation of non-simultaneous records. Our estimate also approaches the quantity tentatively estimated for the population breeding in the region of Madrid (500-750 males) by García de la Morena et al. (2004b). These results seem to confirm the resident status of most Little Bustard nuclei in Madrid (García de la Morena 2002), although the direct inference of reproductive numbers from winter estimates should be avoided until more information on species' movements is gathered, since the region receives some wintering birds from more northern populations (i.e. western France; Morales et al. 2002) or adjacent regions (own unpubl. radiotracking data), and exports wintering individuals to other parts of the Iberian Southern Plateau (own unpubl. radiotracking data).

Our extrapolation procedure considers the number of birds recorded per square kilometre of potential habitat at each individual sector, which provides reasonably realistic estimates, since the proportion of suitable habitat can vary considerably between squares. The use of spatially and physiographically homogeneous sectors contributes to reduced extrapolation errors in relation to the error made if census results were extrapolated directly to the total surface of potentially suitable habitat. This conclusion is supported by two facts: (i) the proportion of potential habitat differs greatly between sectors, so that extrapolations are based on a more realistic availability of suitable habitat, and (ii) the spatial distribution of Little Bustard flocks is also significantly different between sectors.

In this context, the CORINE Land Cover 2000 Project (Büttner et al. 2004) offers a good chance to apply a survey design like this at larger scales (national, peninsular or European level), since it allows identification of potential habitats all over the species' distribution in Europe for medium- or long-term monitoring because habitat definitions are standardized for Europe. The most recent update of CORINE Land Cover (2005) shows a good correspondence in terms of habitat types and precision with the $1: 50,000$ cartography used in this survey for the region of Madrid.

Finally, it is important to emphasize that, as pointed out by Bibby et al. (2000), some previous knowledge of the potential distribution of the species in the region is useful in optimizing survey effort to preferentially cover the areas of greater probability of presence. In this context, our design has proved to be adequate, since no Little Bustard was observed out of the previously known range of the species in the region, in spite of the large area of potential habitat covered during surveys out of that range. 


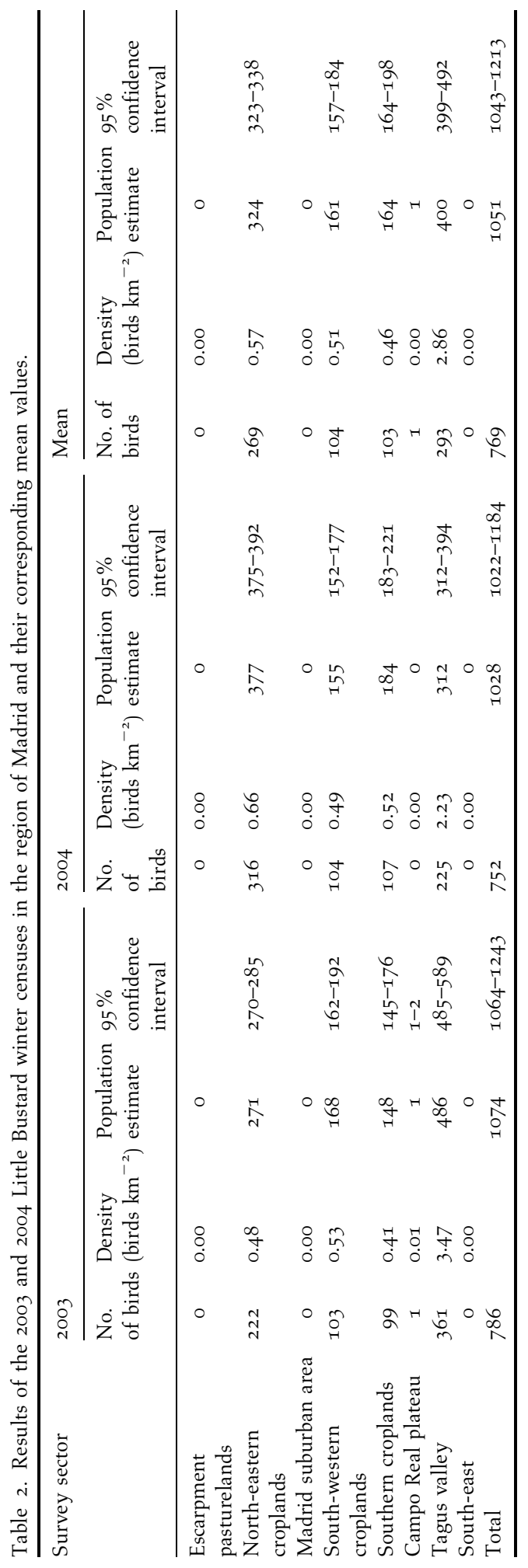


Between-year differences were greater at sector scale, so that wintering populations in sectors such as 'Southern croplands' or 'South-western croplands' seemed to be stable, while they showed noticeable changes in others such as 'North-eastern croplands' and 'Tagus valley'. In these two sectors, CVs were very similar between years, suggesting the arrival of wintering birds from northern to southern sectors. At the square scale, the overall CV was around $53 \%$, which also suggests the existence of between-year population variations within sectors, as well as some variability between areas and populations within the region of Madrid. Nevertheless, all these trends should be confirmed with a longer series of surveys.

In addition to inter-annual comparisons, several other factors should be considered in order to evaluate the general adequacy of this census method. For example, this methodology has been used for several years for weekly and monthly monitoring of wintering Little Bustard populations in smaller areas $\left(35-50 \mathrm{~km}^{2}\right)$ in Toledo and Ciudad Real provinces (also in Central Spain), giving consistent results (own unpubl. data). The average area of potentially suitable habitat surveyed per 10 $\mathrm{km} \times$ 10 $\mathrm{km}$ UTM square in the present study was $44.2 \mathrm{~km}^{2}$ (maximum $89.2 \mathrm{~km}^{2}$ ). Consequently, our census method seems suitable to surveys even more extensive than the one presented here. Additionally, variation due to immigration or emigration is very small over the course of a few days (own unpubl. data), and the extent of daily movements (i.e. from roosts to foraging areas), as shown by radiotracking, is less than $10 \mathrm{~km}$ (García de la Morena et al. in prep.).

\section{Winter distribution}

The main wintering sectors found in the present study ('Tagus valley', 'North-east croplands' and 'Southern croplands') coincide with those published in García de la Morena (2002), although the distribution pattern presented here is more concentrated around the above-mentioned sectors, while the species seems to have disappeared from several others (i.e. 'Campo Real plateau' or 'South-East'). These sectors are dominated by a cereal pseudo-steppe landscape where wintering Little Bustards normally select those habitats with higher availability of limiting resources such as food (green plant material; see Jiguet 2002) and shelter from predators (i.e. vegetation growth), such as winter stubbles with high vegetation cover or some leguminous crops (Morales et al. 2002, own unpubl. data). The absence of wintering Little Bustards in the 'Madrid suburban area' sector could be explained by the rapid transformation of wastelands and extensive croplands in to urbanized areas, as well as the high habitat fragmentation by infrastructures (highways, high-speed railways, etc.) in recent years (see CORINE Land Cover 2000 Project, Büttner et al. 2004), which have resulted in a significant reduction of suitable habitat for the species. In other sectors such as 'Escarpment pasturelands' and 'Campo Real plateau', both located in the upper altitude range of the species $(>800 \mathrm{~m})$, absence of Little Bustard may be explained by the harsher winter conditions, and therefore lower availability of green plant material and vegetation growth (Jiguet 2002). Breeding densities in those sectors, however, are relatively high (García de la Morena et al. 2001). In that context, the 'Escarpment pasturelands' and 'Campo Real plateau' populations can be considered as migratory, while other nuclei would behave as partially migratory or sedentary, a hypothesis supported by recent radiotracking results (García de la Morena et al. in prep, own unpubl. data). Finally, except for a few sites that can be considered exclusively wintering grounds, such as one square of irrigated crops in the 'Tagus valley' which is used by Little Bustards only outside the breeding season, all main wintering sectors seem to receive non-breeding birds from other populations, specially in the South of the region (own unpubl. radiotracking data).

\section{Conservation implications}

The census methodology presented here may help managers and researchers to carry out standardized and repeatable surveys in other wintering areas in order to develop year-round and 
long-term monitoring programmes for Little Bustard populations, at local, regional or national spatial scales. Such monitoring should increase current knowledge on the species' winter ecology, thus contributing to better conservation strategies, as claimed by the species' Action Plan in Europe (De Juana and Martínez 2001). On the other hand, our results show the relevance for wintering Little Bustards of certain sites that hold large concentrations of birds during periods of time even longer than the breeding season, some of which seem to be fairly constant between years, such as the 'North-eastern croplands', 'Southern croplands', 'South-western croplands' and 'Tagus valley' sectors. Most of these wintering sites are not included in protected areas such as Special Protected Areas, Community Interest Sites or Natural Parks $65 \%$ of squares with species presence). In spite of their comparatively small population size (the main Little Bustard populations wintering in Spain are concentrated in Castilla-La Mancha and Extremadura; García de la Morena et al. 2004b), the presence of wintering birds coming from populations outside Madrid confers on these sites conservation relevance at a national and even international scale, especially considering that winter mortality might be a main cause of decline of threatened breeding populations (Morales et al. 2005b). In this context, the disappearance due to urbanization of some wintering sites historically located within the 'Madrid suburban area' that were reported to receive French Little Bustards (Morales et al. 2002) should be viewed with concern, since urbanization is rapidly expanding over all flat and open landscape areas of the region, especially the unprotected ones (CORINE Land Cover 2000 Project, Büttner et al. 2004). This process may lead to a higher concentration of wintering Little Bustards in the remaining fragments of suitable habitat, thereby increasing their vulnerability both to local catastrophes (i.e. rapid disappearance of resources due to, for example, early ploughing of stubbles, or substitution of alfalfa by unsuitable crops) and longer-term mortality factors (i.e. poaching, collision with power lines, etc.).

\section{Acknowledgements}

We are grateful to all the participants and collaborators in the surveys: A. Mirat, Á. Ramírez, B. Molina, C. Galán, C. Clamagirand, C. Martín, C. Palacín, C. Ponce, E. Alcalá, E. Escudero, E. Martín, F. Mesquida, G. González, I. Sánchez, J. Cano, J. Pinilla, J. Traba, J. A. Fimia, J. A. López, J. M. Traverso, J. C. del Moral, L. Pokorny, M. Juan, M. L. Gil , S. Rosellini and S. Sotillos. P. G. Peter Ryan made valuable comments on data analysis. This is a contribution to the CICYT Project: REN 2000-0765. E. L. García was funded by the Ministry of Education's FPU Programme.

\section{References}

Bernis, F. (1966-1971) Aves migradoras Ibéricas. Madrid: Sociedad Española de Ornitología.

Bibby, C. J., Burgess, N. D., Hill, D. A. and Mustoe, S. (2000) Bird census techniques. London: Academic Press.

BirdLife International (2004) Birds in Europe II. Cambridge, U.K.: BirdLife International.

Büttner, G., Feranec, J., Jaffrain, G., Mari, L., Maucha, G. and Soukup, T. (2004) The CORINE Land Cover 2000 Project. Pp. 331-346 in EARSeL eProceedings.

CAM (1998) Plan regional de estrategia territorial de la Comunidad de Madrid. Madrid: Departamento de Política
Ambiental. Dirección General de Urbanismo y Planificación Territorial. Servicio de Planificación Sectorial de la Comunidad de Madrid.

Collar, N. J., Crosby, M. J. and Stattersfield, A. J. (1994) Birds to watch 2: the world list of threatened birds. Cambridge, U.K.: BirdLife International.

Cramp, S. and Simmons, K. E. L. (1980) The birds of the Western Palearctic. London: Oxford University Press.

De Juana, E. and Martínez, C. (1996) Distribution and conservation status of the Little Bustard Tetrax tetrax in the Iberian Peninsula. Ardeola 43: 157-167. 
De Juana, E. and Martínez, C. (2001) European Union Species Action Plan for the Little Bustard (Tetrax tetrax). BirdLife International - European Commission.

Del Hoyo, J., Elliot, A. and Sargatal, J. (1996) Handbook of the birds of the world. Barcelona: Lynx Editions.

Díaz, M., Martí, R., Gómez-Manzaneque, A. and Sánchez, A. E. (1994) Atlas de las aves nidificantes en Madrid. Madrid: Sociedad Española de Ornitología - Agencia de Medio Ambiente, Comunidad de Madrid.

Díaz, M., Asensio, B. and Tellería, J. L. (1996) Aves Ibéricas I. No Passeriformes. Madrid: J. M. Reyero.

Efron, B. and Tibshirani, R. (1986) Bootstrap methods for standard errors, confidence intervals, and other measures of statistical accuracy. Stat. Sci. 1: 54-75.

García de la Morena, E. L. (2002) Sisón Común (Tetrax tetrax). Pp. 142-143 in J. C. Del Moral, B. Molina, J. De la Puente and J. Pérez-Tris, eds. Atlas de las aves invernantes de la Comunidad de Madrid. Madrid: SEO-Monticola and Comunidad de Madrid.

García de la Morena, E. L., Morales, M. B. and García, J. T. (2001) Análisis de la importancia de la ZEPA no. 139 "Estepas cerealistas de los ríos Jarama y Henares para el Sisón Común, en el conjunto de su población en la Comunidad de Madrid". Unpublished report. Sociedad Española de Ornitología.

García de la Morena, E. L., De Juana, E., Martínez, C., Morales, M. B. and Suárez, F. (2003) Sisón Común, Tetrax tetrax. Pp. 232-233 in R. Martí and J. C. del Moral, eds. Atlas de las aves reproductoras de Espańa. Madrid: Dirección General de Conservación de la Naturaleza - Sociedad Espańola de Ornitología.

García de la Morena, E. L., Morales, M. B., Suárez, F. and De Juana, E. (2004a) Do Spanish Little Bustards migrate? New data on long distance movements of the species pp. 79. International Symposium on Ecology and Conservation of Steppe-Land Birds. Lleida 2004. Lleida CTFC-ULL-UBUAM.

García de la Morena, E. L., De Juana, E., Martínez, C., Morales, M. B. and Suárez, F. (2004b) Sisón Común, Tetrax tetrax. Pp. 202-207 in A. Madrońo, C. González and J. C. Atienza, eds. Libro Rojo de las aves de Espańa. Madrid: Dirección General de Conservación de la Naturaleza Sociedad Espańola de Ornitología.

Goriup, P. D. (1994) Little Bustard Tetrax tetrax. Pp. 236-237 in G. M. Tucker and M. F. Heath, eds. Birds in Europe: their conservation status. Cambridge, U.K.: BirdLife International.

Jiguet, F. (2002) Arthropods in diet of Little Bustards Tetrax tetrax during the breeding season in western France. Bird Study 49: 105-109.

Martínez, C. (1994) Habitat selection by the Little Bustard Tetrax tetrax in cultivated areas of Central Spain. Biol. Conserv. 67: 125-128.

Morales, M. B., Suárez, F., García de la Morena, E. L. and De Juana, E. (2002) Movimientos estacionales y conservación de aves esteparias: el ejemplo del Sisón. Quercus 193: 34-39.

Morales, M. B., García, J. T. and Arroyo, B. E. (2005a) Can landscape composition changes predict spatial and annual variation of little bustard male abundance? Anim. Conserv. 8: 167-174.

Morales, M. B., Bretagnolle, V. and Arroyo, B. E. (2005b) Viability of the endangered little bustard Tetrax tetrax population of western France. Biodivers. Cons., 14: 31353150.

Newton, I. (1998) Population limitation in birds. London: Academic Press.

Pinto, M. (1999) Sisão Tetrax tetrax. Pp. 160-161 in G. L. Elias, L. M. Reino, T. Silva, R. Tomé, P. Geraldes, coords. Atlas das aves invernantes do Baixo Alentejo. Lisbon: SPEA.

Rappole, J. H. and McDonald, M. V. (1994) Cause and effect in population declines of migratory birds. Auk 111: 652-60o.

Salamolard, M. and Moreau, C. (1999) Habitat selection by Little Bustard in a cultivated area of France. Bird Study 46: 25-33.

Schulz, H. (1985) A review of the world status and breeding distribution of the Little Bustard. Bustard Studies 2: 131-151.

Sherry, T. W. and Holmes, R. T. (1996) Winter habitat quality, population limita- 
tion and conservation of NeotropicalNeartcic migrant birds. Ecology 77: 36-48.

Silva, J. P., Pinto, M. and Palmeirim, J. M. (2004) Managing landscapes for the little bustard Tetrax tetrax. Lessons from the study of winter habitat selection. Biol. Conserv. 117: 521-528.

Snow, D. W. and Perrins, C. M. (1998) The birds of the western Palearctic. London: Oxford University Press.

Suárez, F. (2004) Aves y agricultura en España peninsular. Una revisión sobre el estado actual de conocimiento y una previsión de futuro. Pp. 223-265 in J. L. Tellería, ed. $L a$ ornitología hoy. Homenaje al profesor Francisco Bernis Madrazo. Madrid: Editorial Complutense.

Wiens, J. A. (1989) The ecology of bird communities. Cambridge, U.K.: Cambridge University Press.

Wolff, A., Paul, J.-F., Martin, J.-L. and Bretagnolle, V. (2001) The benefits of extensive agriculture to birds: the case of the Little Bustard. J. Appl. Ecol. 38: 963-975.

\section{ELADIO L. GARCÍA DE LA MORENA*, MANUEL B. MORALES}

Dpto. de Ecología, Facultad de Ciencias, Universidad Autónoma de Madrid, 28049 Madrid, Spain.

\section{EDUARDO DE JUANA}

Dpto. de Zoología y Antropología, Universidad Complutense de Madrid, 28040 Madrid, Spain.

\section{FRANCISCO SUÁREZ}

Dpto. de Ecología, Facultad de Ciencias, Universidad Autónoma de Madrid, 28049 Madrid, Spain.

${ }^{*}$ Author for correspondence; e-mail: eladio.garcia@uam.es

Received 13 September 2005; revision accepted 13 February 2006 